\title{
The Symbiosis of Virtual Reality Exposure Therapy and Telemental Health: A Review
}

\author{
Triton Ong ${ }^{1 *}$, Hattie Wilczewski ${ }^{1}$, Hiral Soni ${ }^{1}$, Quinn Nisbet ${ }^{1}$, Samantha R. Paige ${ }^{1}$, \\ Janelle F. Barrera ${ }^{1,2}$, Brandon M. Welch ${ }^{1,3}$ and Brian E. Bunnell ${ }^{1,2}$
}

${ }^{1}$ Doxy.me Research, Doxy.me Inc., Rochester, NY, United States, ${ }^{2}$ Biomedical Informatics Center, Public Health and Sciences, Medical University of South Carolina, Charleston, SC, United States, ${ }^{3}$ Innovation in Mental Health Lab, Department of Psychiatry and Behavioral Neurosciences, University of South Florida, Tampa, FL, United States

\section{OPEN ACCESS}

Edited by:

Monika Stojek,

University of Silesia in Katowice,

Poland

Reviewed by:

Sheila A. M. Rauch,

Emory University, United States

Laura E. Watkins,

Emory University, United States

*Correspondence:

Triton Ong

triton.ong@doxy.me

Specialty section:

This article was submitted to Virtual Reality in Medicine,

a section of the journal

Frontiers in Virtual Reality

Received: 03 January 2022 Accepted: 07 February 2022 Published: 25 February 2022

Citation:

Ong T, Wilczewski $H$, Soni $H$, Nisbet $Q$, Paige SR, Barrera JF, Welch BM and Bunnell BE (2022) The Symbiosis of Virtual Reality Exposure Therapy and

Telemental Health: A Review. Front. Virtual Real. 3:848066. doi: 10.3389/frvir.2022.848066
Phobias and related anxiety are common and costly mental health disorders. Experts anticipate the prevalence of phobias will increase due to the COVID-19 pandemic. Exposure therapies have been established as effective and reliable treatments for anxiety, including recent innovations in virtual reality-based exposure therapy (VRET). With the recent advent of telemental health $(\mathrm{TMH})$, VRET is poised to become mainstream. The combination of VRET and TMH has the potential to extend provider treatment options and improve patient care experiences. In this narrative review, we describe how recent events have accelerated VRET + TMH, identify barriers to VRET + TMH implementation, and discuss strategies to navigate those barriers.

Keywords: virtual reality, exposure therapy, VRET, telemedicine, telehealth, phobia, anxiety, mental health

\section{INTRODUCTION}

Phobias are characterized by the overwhelming fear of an object or situation. About one in 10 adults and one in five adolescents are diagnosed with phobia each year (NIMH) (NIMH Specific Phobia, 2022). Phobias and related anxiety disorders cost $\$ 122$ billion in lost productivity and $\$ 135$ billion in health care annually (Konnopka and König, 2020). People living with phobias can experience disadvantages in school, work, and socialization that elevate risks of depression, substance abuse, deteriorating wellbeing, and suicide (Chartier et al., 2003; Wersebe et al., 2018; Salokangas et al., 2019). If untreated, phobias and related anxiety disorders can have serious impacts on the economy, health care systems, and people's daily lives. Unfortunately, as few as $10 \%$ of people with phobias seek professional care, less than half of whom receive successful treatment (Wardenaar et al., 2017; de Vries et al., 2021).

Exposure therapy is the gold standard treatment for phobias and anxiety (Steinman et al., 2016). Using exposure therapy, providers help patients gain control of their fear gradually in controlled settings (Vinograd and Craske, 2020). In-person exposure (often called in vivo exposure therapy; IVET) produces faster and larger symptom improvements with lower rates of relapse compared to non-exposure alternatives (Wolitzky-Taylor et al., 2008). However, staging phobic experiences for IVET can be costly and unfeasible in office settings (Becker et al., 2004; Deacon and Farrell, 2013; Meyer et al., 2014). Providers can guide patients to imagine phobias with programmatic instructions instead of IVET (Hecker, 1990), but imaginal exposure is unideal since providers cannot monitor patient imaginations (Markowitz et al., 2015; Berman et al., 2021). These barriers prevent people with phobias from receiving the most effective and highest quality of care.

Virtual reality (VR) is an emerging solution to the limitations of in vivo and imaginal exposure therapy. Virtual reality-based exposure therapy (VRET) uses computer simulations to evoke the 
same responses as real-life phobic experiences (Gramlich et al., 2021). The physical absence of fearful situations helps patients approach, accept, engage, and adhere more with VRET than IVET with equal or better outcomes (Deng et al., 2019; Wechsler et al., 2019; Horigome et al., 2020). VRET simulations can be made to look, sound, and feel real, resulting in strong ecological validity and transfer of treatment effects (Morina et al., 2015). Providers also benefit from VRET with favorable costs, safety, efficiency, and near total control over patient experiences compared to non-VR exposure therapies (Boeldt et al., 2019). Despite its benefits, mental health providers have not yet embraced VRET for widespread use (Rizzo and Koenig, 2017).

Mental health providers are more likely to adopt a technology if it is easy to use and helps improve patient care, as demonstrated recently with telemedicine (Cowan et al., 2019). Before 2020, mental health providers spent less than $25 \%$ of their time delivering telehealth services (Glueckauf et al., 2018; Bunnell et al., 2020). Unresponsive insurance coverage made telemental health (TMH) difficult to use (Aboujaoude, 2018; Adams et al., 2018). Upon the onset of COVID-19, emergency public health policies granted acceptance of TMH which has since been used to conduct as much as $85 \%$ of mental health services (Pierce et al., 2020; Reilly et al., 2020). Providers and patients now demand these policy changes be made permanent and $\mathrm{TMH}$ uptake become the new norm (Whaibeh et al., 2020; Molfenter et al., 2021; Renn et al., 2021). TMH was once niche but has proven to be an essential care option. VRET is positioned to join that fate in symbiosis.

In this new norm of telemedicine, the human touch of inperson care must be adapted for remote services. VRET is effective for a variety of anxiety and stress-related mental health conditions, demand for which is anticipated to rise in the fallout of COVID-19. The union of telemedicine and VRET can expand clinical options today, prepare for the telehealth landscape of tomorrow, and set the groundwork for the next evolutions of mental health care. In this article, we describe how current events set the stage for remote administration of VRET, how the delivery of VRET via TMH (VRET + TMH) can address trends in mental health demands, and the challenges stakeholders must navigate toward the future.

\section{BACKGROUND AND CONTEXT FOR VRET + TMH}

\section{Mainstream VR Is Here}

VR systems could cost as much as $\$ 250,000$ USD in the 1980s (Sorene, 2014). The advent and development of personal computers produced clinical VR systems around \$10,000 USD in the 1990s (North et al., 1997). Now, some of the most advanced VR systems to date are designed for home entertainment and can be purchased for \$2,000 USD (Greenwald, 2021). Popular all-inone VR systems are available around \$300 USD (Wickens, 2021). Use of VR for mental health has followed these trends with research using as little as \$5 USD of VR equipment (Lindner et al., 2019a; Donker et al., 2019; Patel et al., 2020). Equipment costs are no longer considered a major barrier to VRET (Lindner et al., 2019b), and consumer technology companies are racing to establish mainstream VR adoption. Facebook has dedicated $17 \%$ of its workforce to get VR into one billion homes (Hamilton, 2021). Others like Google, Apple, Sony, and Netflix are also investing heavily in consumer VR and AR (Nanou, 2021). Broad access to sophisticated VR is our present reality.

There is much potential for VR in mental health care. Realtime interaction in VR therapy allows patients to feel more comfortable and present with providers (Mishkind et al., 2017; Park et al., 2019). Because VR feels real, skills practiced and acquired in VR transfer well to real life (Opriş et al., 2012; Morina et al., 2015). The realistic experiences enabled by VR can enhance mental health treatments in ways considered unfeasible for inperson or current telemedicine approaches (e.g., re-experiencing combat for PTSD therapy) (Parsons and Rizzo, 2008; MaplesKeller et al., 2017). VR is also engaging with constant, game-like feedback to promote treatment adherence and outcomes (Benbow and Anderson, 2019). As a result, VR allows patients to practice skills both in real-time with their providers and on their own as part of treatment plans (Chan et al., 2018; Wiederhold and Riva, 2019). These benefits can make VRbased therapies more convenient and flexible than in-person care, more realistic and conducive to therapeutic presence than telemedicine, and unique in its ability to provide tailored simulation experiences for mental health treatment.

\section{We Need VRET + TMH for the Other Pandemic}

These have been hard times for mental health. The COVID-19 pandemic began in early 2020 with sudden and global mandates of social distancing, travel restrictions, and sheltering-in-place. Health care workers suffered extreme social and emotional impacts of the pandemic (Du et al., 2020), and this stress soon spread to the general public (Fang et al., 2020; Liu et al., 2021). Frequent changes in public health policy lead to confusion about personal health practices (Singh and Ravinetto, 2020; The Lancet Infectious Diseases, 2020). Sleep quality declined globally (Gupta et al., 2020; Pérez-Carbonell et al., 2020). People stayed inside under a relentless assault of bad news: police brutality and widespread civil unrest (Taylor, 2021), months-long and devastating wildfires (Arjmand et al., 2021), chronic resource shortages and skirmishes over toilet paper (Labad et al., 2021), reports of giant invasive hornets (Higgins, 2020), announcement of unavoidable climate consequences (McGrath, 2021), and mounting evidence that our online social lives have been manipulated with harmful intent (Hatmaker, 2021; Ortutay, 2021). The state of the world, apparently, keeps getting worse.

Experts now warn of a secondary pandemic in the psychological fallout of COVID-19. About one in five people are at risk for anxiety, phobia, and other mental health disorders due to ongoing isolation, world events, and lockdown conditions (Lyons et al., 2020; Cavicchioli et al., 2021). Elevated symptoms of mental distress have been reported by $31-82 \%$ of the general population (Xiong et al., 2020; Wu et al., 2021). Pandemic unemployment fluctuates while traditional paths to 
professional advancement falter (Berkowitz and Basu, 2021), keeping many under threats of job loss and homelessness (Le and Nguyen, 2021; Lin et al., 2021). With nowhere else to be, sheltering-in-place resulted in escalating rates of domestic abuse (Kovler et al., 2021). School closures delayed the academic, physical, and social development of young people for more than a year (Ghosh et al., 2020; Hoffman and Miller, 2020). Prolonged quarantine increased risks for loneliness, depression, and suicide (Kim and Jung, 2021; Pirkis et al., 2021), especially for those at risk before the pandemic (Chatterjee et al., 2020). Global stress remains high as people worry about their own health and the safety of loved ones (Bonsaksen et al., 2021). The ongoing COVID-19 pandemic and its effects are considered an intergenerational trauma upon peoples' lives and hopes for the future (Bridgland et al., 2021).

At the time of this publication, coordinated health efforts have vaccinated $63 \%$ of the US population against COVID-19 (Carlsen, 2021). In many places, mask mandates have been lifted while international travel and public events rebound. However, hopes of a return to pre-pandemic life are threatened by novel COVID variants which may be deadlier, more contagious, and resistant to previous vaccination (CDC, 2021). Global outbreaks led to the enactment of new public health restrictions, which are being met with widespread protests and violence (BBC News, 2021). COVID-related helplessness seem set to grow among the public. Social avoidance, distrust, anxiety around strangers, compulsive sanitation behaviors, and pervasive fear are now common around the world (Heiat et al., 2021; Lindinger-Sternart et al., 2021; Rosenberg Danziger et al., 2021; Samuels et al., 2021). Pandemic-based phobias may be emerging around hospitals and vaccines, life in public spaces, and screen aversion related to distance learning and remote work (Brown, 2021; McMurdock, 2021; Nardi and Cosci, 2021; Willis et al., 2021; Yakobi and Cheng, 2021). Research, development, and deployment of VRET + TMH will be a critical need for current and future mental health (Shah et al., 2020; Wanling Zhang et al., 2020).

\section{BENEFITS OF VRET + TMH}

Telemedicine has proven to reduce wait times, travel burdens, and the overall stress of patient health care experiences (Lehoux et al., 2000; Gajarawala and Pelkowski, 2021). Mental health services benefit particularly from remote care, allowing patients to seek treatment that feels more private and less stigmatized (Knaak et al., 2017; Goldkind and Wolf, 2021; Renn et al., 2021). However, TMH still leaves some unsatisfied. Patients report feeling unable to express themselves over webcam with limited nonverbal communication, while providers lament their lack of control over remote session settings (Almathami et al., 2020; Steidtmann et al., 2020; Uscher-Pines et al., 2020). Aspects of inperson care that are lost over TMH may be restored and enhanced with VR. VR often utilizes head-mounted displays and real-time motion tracking to create experiences of telepresence, during which users feel that simulated environments are real and distant people are here (Riva et al., 2004; Hilty et al., 2020). Telepresence facilitates gestures and body language like in-person interactions while also isolating users' visual and auditory experience to the virtual environment. The immersive characteristics of VR make it an ideal solution to some common barriers of standard $\mathrm{TMH}$ (Boydstun et al., 2021; Di Carlo et al., 2021; Matamala-Gomez et al., 2021; Pimentel et al., 2021; Sampaio et al., 2021).

Accessibility of VRET is especially important due to stigmas surrounding phobias and anxiety. VRET sessions are commonly conducted in the clinical settings of a therapist's office (Boeldt et al., 2019), which requires therapists to dedicate clinic space to VR arrangements and maintains travel burdens upon patients. It is common for people with phobias to avoid treatment and hide their symptoms, even from their own health care providers (Davidson, 2005; de Oliveira-Souza, 2018; Curcio and Corboy, 2020). Patients seeking phobia treatment often worry about embarrassing themselves in front of therapists (Bush, 2008). In one VRET study, patients in VR were so distracted by the physical presence of others that therapists had to be moved to a separate room (Jang et al., 2002). While clinic-based VRET reduces potential embarrassment for patients with immersion into simulated environments, VRET + TMH stands to extend treatment to the comfort and privacy of patients' homes (Rizzo and Koenig, 2017).

The integration of VRET into TMH creates new options in the treatment of phobias and anxiety. The sensors in VR headsets and software can automate data collection such as patient distance or time spent touching the phobic stimuli, allowing providers to monitor patient progress remotely (Brookes et al., 2020; Krohn et al., 2020; Ratcliffe et al., 2021). Provider access to such data could facilitate patient engagement with VRET on their own time and at their own pace. Randomized trials have demonstrated successful phobia treatment with asynchronous, self-led, low-cost VRET with no negative side effects (Freeman et al., 2018; Lindner et al., 2019a; Donker et al., 2019; Shin et al., 2021). The telemonitoring of asynchronous VRET may be particularly beneficial for populations at risk for untreated phobias such as children, people who experience difficulty leaving their home, or those with limited access to in-person alternatives (Demers et al., 2020).

Scalability is another exciting prospect of VRET + TMH. There are far more patients in need than providers available to serve them, which creates constant demand for clinician force multipliers (Gardner et al., 2020). Provider-supervised digital interventions can streamline treatment delivery and be as effective as standard clinical care (Fairburn and Patel, 2017). For VRET, TMH delivery models can expand providers' treatment options with remote asynchronous monitoring and reach patients beyond the proximity of their clinical offices (Paping et al., 2010). The convenience of automated, self-led, remotely monitored VRET can be impactful for those with subclinical phobia symptoms who may be unlikely to seek treatment (Fehm et al., 2008). Implementation of VRET + $\mathrm{TMH}$ could expand a provider's capacity from one-on-one clinical sessions to mass, simultaneous care in the general population. These potential benefits of clinical scale may also extend the conduct of unsupervised VR research (Persky, 2020; Mottelson et al., 2021). 
VRET + TMH may enhance collaborative session interactions. In IVET, imaginal exposure, and clinic based VRET, providers observe and communicate with a patient undergoing programmed phobic experiences. Synchronous VRET, however, allows the patient and provider to inhabit the same experiential space. Co-immersion in the VRET experience allows the provider to see what the patient sees, adjust the virtual environment in real-time response to the patient's reactions, and interact with the phobic situation in tandem with the patient (Tabbaa et al., 2020). A user's digital body in the virtual environment (i.e., avatar) is another empathetic aspect of VRET + TMH with important implications for mental health care (Rehm et al., 2016). Providers' avatars can be shaped to facilitate rapport, patient comfort, and treatment procedures. In a study of VR-based therapy for eating disorders, patients felt trusting and engaged with treatment because therapists were depicted as cartoonish avatars, which patients characterized as cute, non-judgmental, and conducive to a relaxed atmosphere (Matsangidou et al., 2020). Clinic-based VRET immerses the patient into a therapeutic simulation while the therapist supervises from the outside. VRET $+\mathrm{TMH}$ may bring therapists into the treatment experience with patients.

TMH and VRET are clinical support tools that have proven effective in the treatment of phobias, anxiety, and mental health. Combining TMH and VRET may lead to additive benefits for evidence-based treatment since VR has been shown to enrich remote interactions and $\mathrm{TMH}$ can improve the deployment of VRET. While VRET + TMH can enhance respective clinical toolsets and lead to benefits neither could achieve independently, TMH and VRET each bring their own challenges. It is important to take a realistic view of critical barriers and limitations to realize the potential future of VRET delivered via TMH.

\section{BARRIERS TO VRET + TMH}

Usability has been a concern for clinically oriented VR. It is common for therapeutic VR software to follow design conventions of video games (Tao et al., 2021). This can make VR-based therapy feel disorienting, as people who provide and receive mental health care may not have extensive gaming experience (Tuena et al., 2020; Pimentel et al., 2021). A systematic review found 1,785 VR apps for mental health, but only 11 were rated as potentially beneficial for therapy due to poor functionality (Best et al., 2021). In addition to unintuitive design or lack of therapeutic customization, VR-related motion sickness (often called cybersickness or simulator sickness) remains an issue (Timothy Zhang et al., 2020). Simulator sickness is rare in VRET research, but its occurrence can compromise patient experiences and lead to treatment dropout (Benbow and Anderson, 2019). Self-led digital interventions for mental health have notoriously high dropout rates (Saad et al., 2021), which makes usability a primary emphasis of VRET + $\mathrm{TMH}$. Limiting time spent in VR to $1 \mathrm{~h}$ or less, brief breaks from VR within sessions, and obscuring visual motion indicators help reduce the occurrence and severity of simulator sickness (Chang et al., 2020; Kim et al., 2021). VR research continues to reveal contributing factors and techniques to minimize simulator sickness. Directly involving stakeholders in the development of their own interventions will be a vital practice to ensure optimal engagement, adoption, and ergonomics of remote VR-based therapies (Pizzoli et al., 2019; Tuena et al., 2020).

Safety is critical with emerging patient care technologies. It is unclear what design features, clinical practices, or level of immersion can optimize VRET experiences and outcomes (Botella et al., 2017; Eshuis et al., 2020). VRET allows providers to manipulate patients' cognitive and affective states with illusory experiences, which has equal potential for positive and negative impacts. Detachment from one's identity, body, or surroundings in VR can intensify emotional reactions and has been compared to inducing a temporary dissociative disorder (Parsons, 2021). The negative impacts of VR remain understudied for children and other populations sensitive to change in affect (Kothgassner and Felnhofer, 2021). While a meta-analysis found no substantial evidence of deleterious effects in VR therapies (Fernández-Álvarez et al., 2019), disparate study designs and publication biases may hinder detection of VR side effects (Chesham et al., 2018; Anderson and Molloy, 2020). It will be vital to promote measurement and reporting of VR side effects in research and development (Saredakis et al., 2020).

Special effort must be taken to build rapport and maintain therapeutic relationships over TMH (Glass and Bickler, 2021). While VR can restore nonverbal communication of body posture, head position, and hand gestures, VR does not yet track gaze or facial expressions. The expressionless eyes and faces of virtual characters have been hypothesized to explain weak effects in some VRET research (Kampmann et al., 2016). Facial expressions are vital data for providers to monitor during exposure therapy, but VR headsets do not track or display these data for provider assessment. Developers have acted on this same need for face and gaze tracking in commercial VR applications. HTC released a VR headset attachment to track cheek, mouth, and chin expressions (Stein, 2021). Facebook published internal research of a prototype VR headset that tracks and displays eye movements (Matsuda et al., 2021). Evidence of face and eye tracking features were also found in upcoming versions of Oculus headsets (Heaney, 2021). These are encouraging signals of forthcoming solutions to display face and gaze direction in VR-based therapies, which should be evaluated rapidly for clinical use.

Technical infrastructures are another barrier to VRET + TMH. About 27\% of Americans still do not have access to affordable or reliable broadband internet (Atske, 2019). Less than half of Americans with broadband access choose to use it (McKinley, 2020). Streaming VR of acceptable quality can be achieved at $100 \mathrm{mbps}$ but high-end VR can require $400 \mathrm{Mbps}$ of bandwidth (Mangiante et al., 2017), more than twice the average internet speed in the US (Supan, 2021). Access to VR equipment has also been complicated by COVID-19's impacts on global supply chains and cryptocurrency mining (Molloy, 2021; The Economist, 2021). Digital divides exclude people on the basis of geography, ethnicity, gender, and socioeconomic status (Saeed and Masters, 2021). Clinicians, researchers, developers, and consumers will need to collaborate openly to avoid widening these divides in pursuit of VRET + TMH (Logan et al., 2021). 
Investment and maintenance costs can be deterrents to otherwise effective health care technologies. The tendency for telemedicine to reduce costs for both patients and providers is a leading reason for its success (Almathami et al., 2020). Patients and providers may hesitate with these technologies if the potential financial gains are not apparent. Despite the falling cost of VR equipment, some mental health providers worry that VR can still be too costly (Pimentel et al., 2021). For example, investment in formal training and dedicated staff may be necessary for providers to use VR with confidence (Maples-Keller et al., 2017; Boeldt et al., 2019). However, people are willing to pay if the ends justify the means. A systematic review found that mental health providers are accepting of telemedicine costs if they believe the technology will improve patient outcomes (Harst et al., 2019). Understanding the additive, clinical value of VRET + TMH will be an important area of future research.

\section{DISCUSSION}

Delivery of VRET as part of TMH represents a unique opportunity for cross-pollination between clinical practice, academic research, industry development, and consumer advocacy.

There can be an overwhelming number of choices in VRET + TMH. Considerations must be made for the look, feel, and sound of the VR environment and its contents; screen resolution, refresh rates, control schemes, power supply, sanitation protocols, and device maintenance; user interfaces, therapeutic content, and how all this should be different between providers and patients. It is important to disseminate how and why decisions are made for VRET + TMH to build accumulative and progress-oriented knowledge (Birckhead et al., 2019). The design of VRET, as with other healthcare technologies, is optimized most reliably through iterative collaboration with direct stakeholders (Tabbaa et al., 2020). Numerous case studies and design reports have described user-centered development processes for self-led VRET (North et al., 1997; Hartanto et al., 2016; Bălan et al., 2020). Others have reported on remote VRET user interfaces codesigned with mental health providers and patients (Brinkman et al., 2010; Kornarakis, 2017; Salkevicius and Navickas, 2018; Šalkevičius et al., 2019). Efforts to scale remote VRET have also been published on a remote VRET platform for one provider to treat multiple patients, and a system for automated tailoring of VRET exercises (Paping et al., 2010; Heyse et al., 2018). Usercentered research is critical to develop a systematic understanding of VRET + TMH (Rizzo et al., 2018).

While the future is promising for VRET $+\mathrm{TMH}$, there remains uncertainty about how acceptability and outcomes may vary by treatment populations, practitioner competencies, use cases, and ethics. Studies to date have not focused on diverse participant characteristics that may be relevant to risks and outcomes (Liu et al., 2020; Kaimara et al., 2021; Kothgassner and Felnhofer, 2021). TMH and VRET are not yet standard topics in professional education and training, which leaves providers with lingering hesitation (Cowan et al., 2019; Kourtesis et al., 2019; Hilty et al., 2020). Privacy regulations, practice ethics, and conceptual understandings of VR have not kept pace with the speed of technology advancements (Rizzo et al., 2018; Parker et al., 2019; Marloth et al., 2020; Slater et al., 2020). Principles and recommendations have been published for telebehavioral health technologies in clinical care and training (Maheu et al., 2018; Nazeha et al., 2020; Baier and Danzo, 2021). Such principles should be applied and revisited frequently to refine our understanding and guide the application of VRET + TMH.

As VR and telemedicine technologies continue to mature, practicality will be a leading topic for VRET + TMH. This research is expected to grow due to telemedicine's recent uptake, but previous studies of VRET without TMH show promising cost-effectiveness. VRET for military PTSD saved $\$ 114,000$ USD per patient compared to training a replacement soldier (Wood et al., 2009). Researchers in another study used only \$5 USD of VR equipment, combined with off-the-shelf apps and participants' personal smartphones, for single-session treatment of public speaking phobia (Lindner et al., 2019a). A systematic review concluded that computer simulated VRET can reduce costs compared to staging physical experiences for IVET (Botella et al., 2017), which shows promise for self-led VRET (Reeves et al., 2021). Interdisciplinary collaboration has been recommended and appears to be on the rise with a growing number of open-source VR projects (Boeldt et al., 2019; Geraets et al., 2021). Formal training and protocol manualization will also be necessary for the dissemination of VRET + TMH. A systematic review found that $1 \mathrm{~h}$ sessions, once weekly, for 8-12 weeks, using immersive head-mounted VR were helpful practices for VRET implementation (Krzystanek et al., 2021). Recommendations have also been made for staging the patient's surroundings during VRET with cool temperatures and dim lighting to maximize presence and minimize distractions (Bush, 2008). Collaboration between research, health, VR, and patient groups will be necessary to expand the practical knowledge base for VRET + TMH.

There is a growing variety of off-the-shelf VR solutions that may be used to minimize development challenges and provide clinical benefit. Instead of designing and maintaining computergenerated visuals for VRET, researchers have used consumer camera systems (e.g., GoPro) to make 360 VR videos (StuparRutenfrans et al., 2017; Ionescu et al., 2021). This technique facilitates production of predictable exposure hierarchies with photorealistic visuals and low production costs (Holmberg et al., 2020). Production barriers to VRET + TMH may be further reduced with clinical use of entertainment video games (Pallavicini et al., 2021). Since the early 2000s, people have sought off-label health benefits playing a virtual social game called Second Life (Beard et al., 2009). Researchers were quick to engage Second Life as a platform for health studies and education (Boulos et al., 2007), and notably for exposurebased therapy (Gorini et al., 2008). There is evidence people are using games like VRChat in a similar fashion today; as approximations of self-led VRET. Coping with social anxieties was a leading reason people started to play VRChat during the COVID-19 pandemic (Kelley, 2021; Sykownik et al., 2021). Social VR games can facilitate casual intimacy (Maloney and Freeman, 2020), which may provide opportunity for patients to engage with 
social phobias in low-stake settings. While most mental health VR apps have been rated unlikely to support patient care (Best et al., 2021), there is a growing abundance of other VR apps that may be useful in phobia and anxiety treatment protocols (Lindner et al., 2017). These commercial hardware, video games, and smartphone apps were not made for health purposes but there is ample opportunity to incorporate them into therapy today (Tuerk et al., 2019). Exploration of these commercial options can provide immediate clinical options and guide development of dedicated VRET + TMH solutions (Riva et al., 2020).

\section{CONCLUSION}

Anyone can encounter experiences that inflict a phobia or anxiety disorder. These disorders, if untreated, can cascade into worsening symptoms and decline in quality of life. While inperson IVET is the current gold standard treatment for phobias, clinic-based VRET has emerged as an equally effective and more flexible treatment option. Recent advances in consumer-oriented

\section{REFERENCES}

Aboujaoude, E. (2018). Telemental Health: Why the Revolution Has Not Arrived. World Psychiatry 17, 277-278. doi:10.1002/wps.20551

Adams, S. M., Rice, M. J., Jones, S. L., Herzog, E., Mackenzie, L. J., and Oleck, L. G. (2018). TeleMental Health: Standards, Reimbursement, and Interstate Practice. J. Am. Psychiatr. Nurses Assoc. 24, 295-305. doi:10.1177/1078390318763963

Almathami, H. K. Y., Win, K. T., and Vlahu-Gjorgievska, E. (2020). Barriers and Facilitators that Influence Telemedicine-Based, Real-Time, Online Consultation at Patients' Homes: Systematic Literature Review. J. Med. Internet Res. 22, e16407. doi:10.2196/16407

Anderson, P. L., and Molloy, A. (2020). Maximizing the Impact of Virtual Reality Exposure Therapy for Anxiety Disorders. Curr. Opin. Psychol. 36, 153-157. doi:10.1016/j.copsyc.2020.10.001

Arjmand, H.-A., Seabrook, E., Bakker, D., and Rickard, N. (2021). Mental Health Consequences of Adversity in Australia: National Bushfires Associated with Increased Depressive Symptoms, while COVID-19 Pandemic Associated with Increased Symptoms of Anxiety. Front. Psychol. 12, 635158. doi:10.3389/fpsyg. 2021.635158

Atske, S. (2019). Mobile Technology and Home Broadband 2019. Washington, D.C: Pew Research Center. Available from: https://www.pewresearch.org/internet/ 2019/06/13/mobile-technology-and-home-broadband-2019/ Accessed November 30, 2021).

Baier, A. L., and Danzo, S. (2021). Moving toward a new era of Telepsychology in university Training Clinics: Considerations and Curricula Recommendations. Train. Educ. Prof. Psychol. 15:259-266. doi:10.1037/tep0000359

Bălan, O., Cristea, T., Moise, G., Petrescu, L., Ivașcu, S., Moldoveanu, A., et al. (2020). "eTher - an Assistive Virtual Agent for Acrophobia Therapy in Virtual Reality,” in HCI International 2020 - Late Breaking Papers: Virtual and Augmented Reality (Springer International Publishing), 12-25.

BBC News (2021). Covid: Huge Protests across Europe over New Restrictions. London, United Kingdom: BBC. Available from: https://www.bbc.com/news/ world-europe-59363256 Accessed November 29, 2021).

Beard, L., Wilson, K., Morra, D., and Keelan, J. (2009). A Survey of Health-Related Activities on Second Life. J. Med. Internet Res. 11, e17. doi:10.2196/jmir.1192

Becker, C. B., Zayfert, C., and Anderson, E. (2004). A Survey of Psychologists' Attitudes towards and Utilization of Exposure Therapy for PTSD. Behav. Res. Ther. 42, 277-292. doi:10.1016/s0005-7967(03)00138-4

Benbow, A. A., and Anderson, P. L. (2019). A Meta-Analytic Examination of Attrition in Virtual Reality Exposure Therapy for Anxiety Disorders. J. Anxiety Disord. 61, 18-26. doi:10.1016/j.janxdis.2018.06.006
VR hardware, growing popularity of VR entertainment, and the rapid shift to remote health care create ideal conditions to accelerate research and development of VRET $+\mathrm{TMH}$. The union of TMH and VRET will be essential to meet mental health needs of the ongoing pandemic and beyond NIMH Specific Phobia, 2022.

\section{AUTHOR CONTRIBUTIONS}

All authors listed have made a substantial, direct, and intellectual contribution to the work and approved it for publication.

\section{FUNDING}

BB was funded by the National Institute of Mental Health (Grant Numbers. K23MH118482 and R41MH126734) and BW was funded by the National Cancer Institute (Grant Number. K07CA211786).

Berkowitz, S. A., and Basu, S. (2021). Unemployment Insurance, Health-Related Social Needs, Health Care Access, and Mental Health during the COVID-19 Pandemic. JAMA Intern. Med. 181, 699-702. doi:10.1001/jamainternmed.2020. 7048

Berman, N. C., Hezel, D. M., and Wilhelm, S. (2021). Is My Patient Too Sad to Approach Their Fear? Depression Severity and Imaginal Exposure Outcomes for Patients with OCD. J. Behav. Ther. Exp. Psychiatry 70, 101615. doi:10.1016/j. jbtep.2020.101615

Best, P., Meireles, M., Schroeder, F., Montgomery, L., Maddock, A., Davidson, G., et al. (2021). Freely Available Virtual Reality Experiences as Tools to Support Mental Health Therapy: a Systematic Scoping Review and Consensus Based Interdisciplinary Analysis. J. Technol. Behav. Sci., 1-15. doi:10.1007/s41347021-00214-6

Birckhead, B., Khalil, C., Liu, X., Conovitz, S., Rizzo, A., Danovitch, I., et al. (2019). Recommendations for Methodology of Virtual Reality Clinical Trials in Health Care by an International Working Group: Iterative Study. JMIR Ment. Health 6, e11973. doi:10.2196/11973

Boeldt, D., McMahon, E., McFaul, M., and Greenleaf, W. (2019). Using Virtual Reality Exposure Therapy to Enhance Treatment of Anxiety Disorders: Identifying Areas of Clinical Adoption and Potential Obstacles. Front. Psychiatry 10, 773. doi:10.3389/fpsyt.2019.00773

Bonsaksen, T., Leung, J., Schoultz, M., Thygesen, H., Price, D., Ruffolo, M., et al. (2021). Cross-National Study of Worrying, Loneliness, and Mental Health during the COVID-19 Pandemic: A Comparison between Individuals with and without Infection in the Family. Healthcare 9, 903. doi:10.3390/ healthcare9070903

Botella, C., Fernández-Álvarez, J., Guillén, V., García-Palacios, A., and Baños, R. (2017). Recent Progress in Virtual Reality Exposure Therapy for Phobias: A Systematic Review. Curr. Psychiatry Rep. 19, 42. doi:10.1007/s11920-0170788-4

Boulos, M. N. K., Hetherington, L., and Wheeler, S. (2007). Second Life: an Overview of the Potential of 3-D Virtual Worlds in Medical and Health Education. Health Inf. Libraries J 24, 233-245. doi:10.1111/j.1471-1842.2007. 00733.x

Boydstun, C. D., Pandita, S., Finkelstein-Fox, L., and Difede, J. (2021). Harnessing Virtual Reality for Disaster Mental Health: A Systematic Review. Translational Issues Psychol. Sci. 7, 315-331. doi:10.1037/tps0000282

Bridgland, V. M. E., Moeck, E. K., Green, D. M., Swain, T. L., Nayda, D. M., Matson, L. A., et al. (2021). Why the COVID-19 Pandemic Is a Traumatic Stressor. PLoS One 16, e0240146. doi:10.1371/journal.pone.0240146

Brinkman, W.-P., Mast, C. v. d., Sandino, G., Sandino, L. T., and Emmelkamp, P. M. G. (2010). The Therapist User Interface of a Virtual Reality Exposure 
Therapy System in the Treatment of Fear of Flying. Interacting Comput. 22, 299-310. doi:10.1016/j.intcom.2010.03.005

Brookes, J., Warburton, M., Alghadier, M., Mon-Williams, M., and Mushtaq, F. (2020). Studying Human Behavior with Virtual Reality: The Unity Experiment Framework. Behav. Res. 52, 455-463. doi:10.3758/s13428-019-01242-0

Brown, M. (2021). Remote Work Anxiety Is Crippling Employee Mental Health. Albany, NY: breeze. Available from: https://www.meetbreeze.com/blog/ remote-work-anxiety-employees-survey/ Accessed October 28, 2021).

Bunnell, B. E., Barrera, J. F., Paige, S. R., Turner, D., and Welch, B. M. (2020). Acceptability of Telemedicine Features to Promote its Uptake in Practice: A Survey of Community Telemental Health Providers. Int. J. Environ. Res. Public Health 17, 8525. doi:10.3390/ijerph17228525

Bush, J. (2008). Viability of Virtual Reality Exposure Therapy as a Treatment Alternative. Comput. Hum. Behav. 24, 1032-1040. doi:10.1016/j.chb.2007. 03.006

Carlsen, A. (2021). How Is the COVID-19 Vaccination Campaign Going in Your State. Washington, D.C: NPR. Available from: https:/www.npr.org/sections/healthshots/2021/01/28/960901166/how-is-the-covid-19-vaccination-campaign-goingin-your-state (Accessed October 27, 2021).

Cavicchioli, M., Ferrucci, R., Guidetti, M., Canevini, M. P., Pravettoni, G., and Galli, F. (2021). What Will Be the Impact of the Covid-19 Quarantine on Psychological Distress? Considerations Based on a Systematic Review of Pandemic Outbreaks. Healthcare 9, 101. doi:10.3390/healthcare9010101

CDC (2021). What You Need to Know about Variants. Available from: https:// www.cdc.gov/coronavirus/2019-ncov/variants/variant.html (Accessed October 22, 2021).

Chan, S., Li, L., Torous, J., Gratzer, D., and Yellowlees, P. M. (2018). Review of Use of Asynchronous Technologies Incorporated in Mental Health Care. Curr. Psychiatry Rep. 20, 85. doi:10.1007/s11920-018-0954-3

Chang, E., Kim, H. T., and Yoo, B. (2020). Virtual Reality Sickness: A Review of Causes and Measurements. Int. J. Human-Computer Interaction 36, 1658-1682. doi:10.1080/10447318.2020.1778351

Chartier, M. J., Walker, J. R., and Stein, M. B. (2003). Considering Comorbidity in Social Phobia. Soc. Psychiatry Psychiatr. Epidemiol. 38, 728-734. doi:10.1007/ s00127-003-0720-6

Chatterjee, S. S., Barikar, C. M., and Mukherjee, A. (2020). Impact of COVID-19 Pandemic on Pre-existing Mental Health Problems. Asian J. Psychiatry 51, 102071. doi:10.1016/j.ajp.2020.102071

Chesham, R. K., Malouff, J. M., and Schutte, N. S. (2018). Meta-Analysis of the Efficacy of Virtual Reality Exposure Therapy for Social Anxiety. Behav. Change 35, 152-166. doi:10.1017/bec.2018.15

Cowan, K. E., McKean, A. J., Gentry, M. T., and Hilty, D. M. (2019). Barriers to Use of Telepsychiatry: Clinicians as Gatekeepers. Mayo Clinic Proc. 94, 2510-2523. doi:10.1016/j.mayocp.2019.04.018

Curcio, C., and Corboy, D. (2020). Stigma and Anxiety Disorders: A Systematic Review. Stigma and Health 5, 125-137. doi:10.1037/sah0000183

Davidson, J. (2005). Contesting Stigma and Contested Emotions: Personal Experience and Public Perception of Specific Phobias. Soc. Sci. Med. 61, 2155-2164. doi:10.1016/j.socscimed.2005.04.030

de Oliveira-Souza, R. (2018). Phobia of the Supernatural: A Distinct but Poorly Recognized Specific Phobia with an Adverse Impact on Daily Living. Front. Psychiatry 9, 590. doi:10.3389/fpsyt.2018.00590

de Vries, Y. A., Vigo, D., Chiu, W. T., Sampson, N. A., Al-Hamzawi, A., Alonso, J., et al. (2021). Perceived Helpfulness of Treatment for Specific Phobia: Findings from the World Mental Health Surveys. J. Affective Disord. 288, 199-209. doi:10.1016/j.jad.2021.04.001

Deacon, B. J., and Farrell, N. R. (2013). "Therapist Barriers to the Dissemination of Exposure Therapy," in Handbook of Treating Variants and Complications in Anxiety Disorders. Editors E. A. Storch and D. McKay (New York, NY: Springer), 363-373. doi:10.1007/978-1-4614-6458-7_23

Demers, M., Martinie, O., Winstein, C., and Robert, M. T. (2020). Active Video Games and Low-Cost Virtual Reality: An Ideal Therapeutic Modality for Children with Physical Disabilities during a Global Pandemic. Front. Neurol. 11, 601898. doi:10.3389/fneur.2020.601898

Deng, W., Hu, D., Xu, S., Liu, X., Zhao, J., Chen, Q., et al. (2019). The Efficacy of Virtual Reality Exposure Therapy for PTSD Symptoms: A Systematic Review and Meta-Analysis. J. Affective Disord. 257, 698-709. doi:10.1016/j.jad.2019. 07.086
Di Carlo, F., Sociali, A., Picutti, E., Pettorruso, M., Vellante, F., Verrastro, V., et al. (2021). Telepsychiatry and Other Cutting-Edge Technologies in COVID-19 Pandemic: Bridging the Distance in Mental Health Assistance. Int. J. Clin. Pract. 75, 716. doi:10.1111/ijcp. 13716

Donker, T., Cornelisz, I., van Klaveren, C., van Straten, A., Carlbring, P., Cuijpers, P., et al. (2019). Effectiveness of Self-Guided App-Based Virtual Reality Cognitive Behavior Therapy for Acrophobia: A Randomized Clinical Trial. JAMA Psychiatry 76, 682-690. doi:10.1001/jamapsychiatry.2019.0219

Du, J., Dong, L., Wang, T., Yuan, C., Fu, R., Zhang, L., et al. (2020). Psychological Symptoms Among Frontline Healthcare Workers during COVID-19 Outbreak in Wuhan. Gen. Hosp. Psychiatry 67, 144-145. doi:10.1016/j.genhosppsych. 2020.03.011

Eshuis, L. V., van Gelderen, M. J., van Zuiden, M., Nijdam, M. J., Vermetten, E., et al. (2020). Efficacy of Immersive PTSD Treatments: A Systematic Review of Virtual and Augmented Reality Exposure Therapy and a Meta-Analysis of Virtual Reality Exposure Therapy. J. Psychiatr. Res. 143, 516-527. doi:10.1016/j. jpsychires.2020.11.030

Fairburn, C. G., and Patel, V. (2017). The Impact of Digital Technology on Psychological Treatments and Their Dissemination. Behav. Res. Ther. 88, 19-25. doi:10.1016/j.brat.2016.08.012

Fang, X., Zhang, J., Teng, C., Zhao, K., Su, K.-P., Wang, Z., et al. (2020). Depressive Symptoms in the Front-Line Non-medical Workers during the COVID-19 Outbreak in Wuhan. J. Affective Disord. 276, 441-445. doi:10.1016/j.jad.2020. 06.078

Fehm, L., Beesdo, K., Jacobi, F., and Fiedler, A. (2008). Social Anxiety Disorder above and below the Diagnostic Threshold: Prevalence, Comorbidity and Impairment in the General Population. Soc. Psychiat Epidemiol. 43, 257-265. doi:10.1007/s00127-007-0299-4

Fernández-Álvarez, J., Rozental, A., Carlbring, P., Colombo, D., Riva, G., Anderson, P. L., et al. (2019). Deterioration Rates in Virtual Reality Therapy: An Individual Patient Data Level Meta-Analysis. J. Anxiety Disord. 61, 3-17. doi:10.1016/j.janxdis.2018.06.005

Freeman, D., Haselton, P., Freeman, J., Spanlang, B., Kishore, S., Albery, E., et al. (2018). Automated Psychological Therapy Using Immersive Virtual Reality for Treatment of Fear of Heights: a Single-Blind, Parallel-Group, Randomised Controlled Trial. The Lancet Psychiatry 5, 625-632. doi:10.1016/s2215-0366(18)30226-8

Gajarawala, S. N., and Pelkowski, J. N. (2021). Telehealth Benefits and Barriers. J. Nurse Pract. 17, 218-221. doi:10.1016/j.nurpra.2020.09.013

Gardner, J. S., Plaven, B. E., Yellowlees, P., and Shore, J. H. (2020). Remote Telepsychiatry Workforce: a Solution to Psychiatry's Workforce Issues. Curr. Psychiatry Rep. 22, 8. doi:10.1007/s11920-020-1128-7

Geraets, C. N. W., van der Stouwe, E. C. D., Pot-Kolder, R., and Veling, W. (2021). Advances in Immersive Virtual Reality Interventions for Mental Disorders: A New Reality? Curr. Opin. Psychol. 41, 40-45. doi:10.1016/j.copsyc.2021.02.004

Ghosh, R., Dubey, M. J., Chatterjee, S., and Dubey, S. (2020). Impact of COVID -19 on Children: Special Focus on the Psychosocial Aspect. Minerva Pediatr. 72, 226-235. doi:10.23736/S0026-4946.20.05887-9

Glass, V. Q., and Bickler, A. (2021). Cultivating the Therapeutic Alliance in a Telemental Health Setting. Contemp. Fam. Ther. 43, 189-198. doi:10.1007/ s10591-021-09570-0

Glueckauf, R. L., Maheu, M. M., Drude, K. P., Wells, B. A., Wang, Y., Gustafson, D. J., et al. (2018). Survey of Psychologists' Telebehavioral Health Practices: Technology Use, Ethical Issues, and Training Needs. Prof. Psychol. Res. Pract. 49, 205-219. doi:10.1037/pro0000188

Goldkind, L., and Wolf, L. (2021). "That's the Beauty of it": Practitioners Describe the Affordances of Direct to Consumer Tele-Mental Health. Fam. Soc. 102, 1044389421997796. doi:10.1177/1044389421997796

Gorini, A., Gaggioli, A., Vigna, C., and Riva, G. (2008). A Second Life for eHealth: Prospects for the Use of 3-D Virtual Worlds in Clinical Psychology. J. Med. Internet Res. 10, e21. doi:10.2196/jmir.1029

Gramlich, M. A., Smolenski, D. J., Norr, A. M., Rothbaum, B. O., Rizzo, A. A., Andrasik, F., et al. (2021). Psychophysiology during Exposure to Trauma Memories: Comparative Effects of Virtual Reality and Imaginal Exposure for Posttraumatic Stress Disorder. Depress. Anxiety 38, 626-638. doi:10. $1002 /$ da. 23141

Greenwald, W. (2021). The Best VR Headsets for 2021. New York, NY: PC Magazine. Available from: https://www.pcmag.com/picks/the-best-vrheadsets (Accessed August 16, 2021). 
Gupta, R., Grover, S., Basu, A., Krishnan, V., Tripathi, A., Subramanyam, A., et al. (2020). Changes in Sleep Pattern and Sleep Quality during COVID-19 Lockdown. Indian J. Psychiatry 62, 370-378. doi:10.4103/psychiatry. IndianJPsychiatry_523_20

Hamilton, I. (2021). Nearly 20\% of Facebook's Employees Are Working on VR/AR. Los Angeles, CA: Upload. Available from: https://uploadvr.com/facebookemployees-2021/ (Accessed March 18, 2021).

Harst, L., Lantzsch, H., and Scheibe, M. (2019). Theories Predicting End-User Acceptance of Telemedicine Use: Systematic Review. J. Med. Internet Res. 21, e13117. doi:10.2196/13117

Hartanto, D., Brinkman, W.-P., Kampmann, I. L., Morina, N., Emmelkamp, P. G. M., and Neerincx, M. A. (2016). Home-based Virtual Reality Exposure Therapy with Virtual Health Agent Support. Springer International Publishing, 85-98. doi:10.1007/978-3-319-32270-4_9

Hatmaker, T. (2021). Watch Lawmakers Grill Snap, TikTok and YouTube on Kids' Online Safety. San Francisco, CA: TechCrunch. Available from: http:// techcrunch.com/2021/10/25/snap-tiktok-youtube-senate-hearing-congress/ (Accessed October 27, 2021).

Heaney, D. (2021). 'Quest Pro' Face \& Eye Tracking References Found in Oculus Firmware. Los Angeles, CA: UploadVR. Available from: https://uploadvr.com/ quest-pro-face-eye-tracking-oculus-firmware/ (Accessed September 20, 2021).

Hecker, J. E. (1990). Emotional Processing in the Treatment of Simple Phobia: A Comparison of Imaginal and In Vivo Exposure. Behav. Psychother. 18, 21-34. doi:10.1017/s0141347300017961

Heiat, M., Heiat, F., Halaji, M., Ranjbar, R., Tavangar Marvasti, Z., Yaali-Jahromi, E., et al. (2021). Phobia and Fear of COVID-19: Origins, Complications and Management, a Narrative Review. Ann. Ig. 33, 360-370. doi:10.7416/ai.2021. 2446

Heyse, J., Ongenae, F., De Backere, F., and De Turck, F. (2018). "Personalisation of Exercises in VRET," in Workshops at the Thirty-Second AAAI Conference on Artificial Intelligence, New Orleans, USA, January 2018. Available from: https:// www.aaai.org/ocs/index.php/WS/AAAIW18/paper/view/17212 (Accessed July 21, 2021).

Higgins, A. (2020). 'Murder Hornets' Are Creating a Buzz, but Relax. The Sightings Don't Signal End Times. Washington, D.C: The Washington Post. Available from: https://www.washingtonpost.com/lifestyle/home/a-giant-hornet-iscreating-a-buzz-but-relax-the-sightings-dont-signal-end-times/2020/05/19/ b4d240b8-9544-11ea-91d7-cf4423d47683_story.html (Accessed August 6, 2021).

Hilty, D. M., Randhawa, K., Maheu, M. M., McKean, A. J. S., Pantera, R., Mishkind, M. C., et al. (2020). A Review of Telepresence, Virtual Reality, and Augmented Reality Applied to Clinical Care. J. Technol. Behav. Sci. 5, 178-205. doi:10.1007/ s41347-020-00126-x

Hoffman, J. A., and Miller, E. A. (2020). Addressing the Consequences of School Closure Due to COVID-19 on Children's Physical and Mental Well-Being. World Med. Health Pol. 12, 300-310. doi:10.1002/wmh3.365

Holmberg, T. T., Eriksen, T. L., Petersen, R., Frederiksen, N. N., DamgaardSørensen, U., and Lichtenstein, M. B. (2020). Social Anxiety Can Be Triggered by 360-Degree Videos in Virtual Reality: A Pilot Study Exploring Fear of Shopping. Cyberpsychology, Behav. Soc. Networking 23, 495-499. doi:10.1089/ cyber.2019.0295

Horigome, T., Kurokawa, S., Sawada, K., Kudo, S., Shiga, K., Mimura, M., et al. (2020). Virtual Reality Exposure Therapy for Social Anxiety Disorder: a Systematic Review and Meta-Analysis. Psychol. Med. 50, 2487-2497. doi:10. 1017/s0033291720003785

Ionescu, A., Van Daele, T., Rizzo, A., Blair, C., and Best, P. (2021). $360^{\circ}$ Videos for Immersive Mental Health Interventions: a Systematic Review. J. Technol. Behav. Sci. 6, 631-651. doi:10.1007/s41347-021-00221-7

Jang, D. P., Ku, J. H., Choi, Y. H., Wiederhold, B. K., Nam, S. W., Kim, I. Y., et al. (2002). The Development of Virtual Reality Therapy (VRT) System for the Treatment of Acrophobia and Therapeutic Case. IEEE Trans. Inform. Technol. Biomed. 6, 213-217. doi:10.1109/titb.2002.802374

Kaimara, P., Oikonomou, A., and Deliyannis, I. (2021). Could Virtual Reality Applications Pose Real Risks to Children and Adolescents? A Systematic Review of Ethical Issues and Concerns. Virtual Real., 1-39. doi:10.1007/ s10055-021-00563-w

Kampmann, I. L., Emmelkamp, P. M. G., Hartanto, D., Brinkman, W.-P., Zijlstra, B. J. H., and Morina, N. (2016). Exposure to Virtual Social Interactions in the
Treatment of Social Anxiety Disorder: A Randomized Controlled Trial. Behav. Res. Ther. 77, 147-156. doi:10.1016/j.brat.2015.12.016

Kelley, B. (2021). "The Rise of the 'Quarantine Bar Simulator': The Uses and Gratifications of Social VR during the COVID-19 Pandemic," in Proceeding of the 2021 4th International Conference on Information and Computer Technologies (ICICT), HI, USA, March 2021 (IEEE), 216-221.

Kim, H. H.-S., and Jung, J. H. (2021). Social Isolation and Psychological Distress during the COVID-19 Pandemic: A Cross-National Analysis. Gerontologist 61, 103-113. doi:10.1093/geront/gnaa168

Kim, H., Kim, D. J., Chung, W. H., Park, K.-A., Kim, J. D. K., Kim, D., et al. (2021). Clinical Predictors of Cybersickness in Virtual Reality (VR) Among Highly Stressed People. Sci. Rep. 11, 12139. doi:10.1038/s41598-021-91573-w

Knaak, S., Mantler, E., and Szeto, A. (2017). Mental Illness-Related Stigma in Healthcare. Healthc. Manage. Forum 30, 111-116. doi:10.1177/ 0840470416679413

Konnopka, A., and König, H. (2020). Economic Burden of Anxiety Disorders: A Systematic Review and Meta-Analysis. Pharmacoeconomics 38, 25-37. doi:10. 1007/s40273-019-00849-7

Kornarakis, I. (2017). A Virtual Reality Serious Game Platform to Support Treatment of Phobia Patients. Available from: https://apothesis.lib.hmu.gr/ handle/20.500.12688/8064 Accessed July 22, 2021).

Kothgassner, O. D., and Felnhofer, A. (2021). Lack of Research on Efficacy of Virtual Reality Exposure Therapy (VRET) for Anxiety Disorders in Children and Adolescents : A Systematic Review. Neuropsychiatr. 35, 68-75. doi:10.1007/ s40211-020-00349-7

Kourtesis, P., Collina, S., Doumas, L. A. A., and MacPherson, S. E. (2019). Technological Competence Is a Pre-condition for Effective Implementation of Virtual Reality Head Mounted Displays in Human Neuroscience: A Technological Review and Meta-Analysis. Front. Hum. Neurosci. 13, 342. doi:10.3389/fnhum.2019.00342

Kovler, M. L., Ziegfeld, S., Ryan, L. M., Goldstein, M. A., Gardner, R., Garcia, A. V., et al. (2021). Increased Proportion of Physical Child Abuse Injuries at a Level I Pediatric Trauma center during the Covid-19 Pandemic. Child. Abuse Neglect 116, 104756. doi:10.1016/j.chiabu.2020.104756

Krohn, S., Tromp, J., Quinque, E. M., Belger, J., Klotzsche, F., Rekers, S., et al. (2020). Multidimensional Evaluation of Virtual Reality Paradigms in Clinical Neuropsychology: Application of the VR-Check Framework. J. Med. Internet Res. 22, e16724. doi:10.2196/16724

Krzystanek, M., Surma, S., Stokrocka, M., Romańczyk, M., Przybyło, J., Krzystanek, N., et al. (2021). Tips for Effective Implementation of Virtual Reality Exposure Therapy in Phobias-A Systematic Review. Front. Psychiatry 12, 737351. doi:10. 3389/fpsyt.2021.737351

Labad, J., González-Rodríguez, A., Cobo, J., Puntí, J., and Farré, J. M. (2021). A Systematic Review and Realist Synthesis on Toilet Paper Hoarding: COVID or Not COVID, that Is the Question. PeerJ 9, e10771. doi:10.7717/peerj.10771

Le, K., and Nguyen, M. (2021). The Psychological Consequences of COVID-19 Lockdowns. Int. Rev. Appl. Econ. 35, 147-163. doi:10.1080/02692171.2020. 1853077

Lehoux, P., Battista, R. N., and Lance, J.-M. (2000). Telehealth: Passing Fad or Lasting Benefits? Can. J. Public Health 91, 277-280. doi:10.1007/bf03404289

Lin, W., Shao, Y., Li, G., Guo, Y., and Zhan, X. (2021). The Psychological Implications of COVID-19 on Employee Job Insecurity and its Consequences: The Mitigating Role of Organization Adaptive Practices. J. Appl. Psychol. 106, 317-329. doi:10.1037/apl0000896

Lindinger-Sternart, S., Kaur, V., Widyaningsih, Y., and Patel, A. K. (2021). COVID-19 Phobia across the World: Impact of Resilience on COVID-19 Phobia in Different Nations. Couns. Psychother Res. 21, 290-302. doi:10. 1002/capr.12387

Lindner, P., Miloff, A., Hamilton, W., Reuterskiöld, L., Andersson, G., Powers, M. B., et al. (2017). Creating State of the Art, Next-Generation Virtual Reality Exposure Therapies for Anxiety Disorders Using Consumer Hardware Platforms: Design Considerations and Future Directions. Cogn. Behav. Ther. 46, 404-420. doi:10.1080/16506073.2017.1280843

Lindner, P., Miloff, A., Fagernäs, S., Andersen, J., Sigeman, M., Andersson, G., et al. (2019a). Therapist-led and Self-Led One-Session Virtual Reality Exposure Therapy for Public Speaking Anxiety with Consumer Hardware and Software: A Randomized Controlled Trial. J. Anxiety Disord. 61, 45-54. doi:10.1016/j.janxdis.2018.07.003 
Lindner, P., Miloff, A., Zetterlund, E., Reuterskiöld, L., Andersson, G., and Carlbring, P. (2019b). Attitudes toward and Familiarity with Virtual Reality Therapy Among Practicing Cognitive Behavior Therapists: A Cross-Sectional Survey Study in the Era of Consumer VR Platforms. Front. Psychol. 10, 176. doi:10.3389/fpsyg.2019.00176

Liu, Q., Wang, Y., Tang, Q., and Liu, Z. (2020). Do You Feel the Same as I Do? Differences in Virtual Reality Technology Experience and Acceptance between Elderly Adults and College Students. Front. Psychol. 11, 573673. doi:10.3389/ fpsyg.2020.573673

Liu, C., Lee, Y. C., Lin, Y. L., and Yang, S. Y. (2021). Factors Associated with Anxiety and Quality of Life of the Wuhan Populace during the COVID-19 Pandemic. Stress and Health 37, 887-897. doi:10.1002/smi.3040

Logan, D. E., Simons, L. E., Caruso, T., Gold, J. I., Greenleaf, W., Griffin, A., et al. (2021). Leveraging VR/AR to Combat Chronic Pain in Youth: Position Paper from the Interdisciplinary Network on Virtual and Augmented (AR/VR) Technologies for Pain (INOVATE-Pain) Management. J. Med. Internet Res. 23, e25916. doi:10.2196/25916

Lyons, D., Frampton, M., Naqvi, S., Donohoe, D., Adams, G., and Glynn, K. (2020). Fallout from the COVID-19 Pandemic - Should We Prepare for a Tsunami of post Viral Depression. Ir. J. Psychol. Med. 37, 295-300. doi:10.1017/ipm. 2020.40

Maheu, M. M., Drude, K. P., Hertlein, K. M., Lipschutz, R., Wall, K., and Hilty, D. M. (2018). Correction to: An Interprofessional Framework for Telebehavioral Health Competencies. J. Technol. Behav. Sci. 3, 108-140. doi:10.1007/s41347018-0046-6

Maloney, D., and Freeman, G. (2020). "Falling Asleep Together: What Makes Activities in Social Virtual Reality Meaningful to Users," in Proceedings of the Annual Symposium on Computer-Human Interaction in Play, New York, NY, USA, November 2020 (New York, NY: Association for Computing Machinery), 510-521.

Mangiante, S., Klas, G., Navon, A., GuanHua, Z., Ran, J., and Silva, M. D. (2017). "VR Is on the Edge: How to Deliver $360^{\circ}$ Videos in Mobile Networks," in Proceedings of the Workshop on Virtual Reality and Augmented Reality Network VR/AR Network '17, New York, NY, USA, August 2017 (New York, NY: Association for Computing Machinery), 30-35.

Maples-Keller, J. L., Bunnell, B. E., Kim, S.-J., and Rothbaum, B. O. (2017). The Use of Virtual Reality Technology in the Treatment of Anxiety and Other Psychiatric Disorders. Harv. Rev. Psychiatry 25, 103-113. doi:10.1097/hrp. 0000000000000138

Markowitz, J. C., Petkova, E., Neria, Y., Van Meter, P. E., Hembree, E., et al. (2015). Is Exposure Necessary? A Randomized Clinical Trial of Interpersonal Psychotherapy for PTSD. Am. J. Psychiatry 172, 430-440. doi:10.1176/appi. ajp.2014.14070908

Marloth, M., Chandler, J., and Vogeley, K. (2020). Psychiatric Interventions in Virtual Reality: Why We Need an Ethical Framework. Camb. Q. Healthc. Ethics 29, 574-584. doi:10.1017/s0963180120000328

Matamala-Gomez, M., Bottiroli, S., Realdon, O., Riva, G., Galvagni, L., Platz, T., et al. (2021). Telemedicine and Virtual Reality at Time of COVID-19 Pandemic: An Overview for Future Perspectives in Neurorehabilitation. Front. Neurol. 12, 646902. doi:10.3389/fneur.2021.646902

Matsangidou, M., Otkhmezuri, B., Ang, C. S., Avraamides, M., Riva, G., Gaggioli, A., et al. (2020). "Now I Can See Me" Designing a Multi-User Virtual Reality Remote Psychotherapy for Body Weight and Shape Concerns. Human-Computer Interaction, 1-27. doi:10.1080/07370024. 2020.1788945

Matsuda, N., Wheelwright, B., Hegland, J., and Lanman, D. (2021). Reverse PassThrough VR. Facebook Research. Available from: https://research.fb.com/ publications/reverse-pass-through-vr/ Accessed September 20, 2021).

McGrath, M. (2021). Climate Change: IPCC Report Is "Code Red for humanity.". London, United Kingdom: BBC. Available from: https://www.bbc.com/news/ science-environment-58130705 (Accessed August 25, 2021).

McKinley, S. (2020). Microsoft Airband: An Annual Update on Connecting Rural America. Redmond, WA: Microsoft. Available from: https://blogs.microsoft. com/on-the-issues/2020/03/05/update-connecting-rural-america/ (Accessed August 20, 2021)

McMurdock, M. (2021). Student Survey: Depression, Stress and Anxiety Leading Barriers to Learning as Access to Trusted Adults Drops. Los Angeles, CA: LA School Report. Available from: http://laschoolreport. com/student-survey-depression-stress-and-anxiety-leading-barriers-tolearning-as-access-to-trusted-adults-drops/ (Accessed October 28, 2021).

Meyer, J. M., Farrell, N. R., Kemp, J. J., Blakey, S. M., and Deacon, B. J. (2014). Why Do Clinicians Exclude Anxious Clients from Exposure Therapy? Behav. Res. Ther. 54, 49-53. doi:10.1016/j.brat.2014.01.004

Mishkind, M. C., Norr, A. M., Katz, A. C., and Reger, G. M. (2017). Review of Virtual Reality Treatment in Psychiatry: Evidence versus Current Diffusion and Use. Curr. Psychiatry Rep. 19, 80. doi:10.1007/s11920-017-0836-0

Molfenter, T., Heitkamp, T., Murphy, A. A., Tapscott, S., Behlman, S., and Cody, O. J. (2021). Use of Telehealth in Mental Health (MH) Services during and after COVID-19. Community Ment. Health J. 57, 1244-1251. doi:10.1007/s10597021-00861-2

Molloy, D. (2021). The Great Graphics Card Shortage of 2020 (And 2021). London, United Kingdom: BBC. Available from: https://www.bbc.com/news/ technology-55755820 (Accessed September 21, 2021).

Morina, N., Ijntema, H., Meyerbröker, K., and Emmelkamp, P. M. G. (2015). Can Virtual Reality Exposure Therapy Gains Be Generalized to Real-Life? A MetaAnalysis of Studies Applying Behavioral Assessments. Behav. Res. Ther. 74, 18-24. doi:10.1016/j.brat.2015.08.010

Mottelson, A., Petersen, G. B., Lilija, K., and Makransky, G. (2021). Conducting Unsupervised Virtual Reality User Studies Online. Front. Virtual Reality 2, 66. doi:10.3389/frvir.2021.681482

Nanou, E. (2021). Is Virtual Reality Really the Future of Everything. St. Laurent, Quebec, CA: Make Use Of. Available from: https://www.makeuseof.com/ virtual-reality-future-of-everything/ (Accessed March 25, 2021).

Nardi, A. E., and Cosci, F. (2021). Expert Opinion in Anxiety Disorder: Coronaphobia, the New Face of Anxiety. Personalized Med. Psychiatry 25-26, 100070. doi:10.1016/j.pmip.2021.100070

Nazeha, N., Pavagadhi, D., Kyaw, B. M., Car, J., Jimenez, G., and Tudor Car, L. (2020). A Digitally Competent Health Workforce: Scoping Review of Educational Frameworks. J. Med. Internet Res. 22, e22706. doi:10.2196/22706

NIMH Specific Phobia (2022). National Institute of Mental Health. Available from: https://www.nimh.nih.gov/health/statistics/specific-phobia (Accessed August 13, 2021).

North, M. M., North, S. M., and Coble, J. R. (1997). Virtual Environments Psychotherapy: A Case Study of Fear of Flying Disorder. Presence: Teleoperators \& Virtual Environments 6, 127-132. doi:10.1162/pres.1997.6. 1.127

Opriş, D., Pintea, S., García-Palacios, A., Botella, C., Szamosközi, Ş., and David, D. (2012). Virtual Reality Exposure Therapy in Anxiety Disorders: a Quantitative Meta-Analysis. Depress. Anxiety 29, 85-93. doi:10.1002/da.20910

Ortutay, B. (2021). People or Profit? Facebook Papers Show Deep Conflict within. New York, NY: AP News. Available from: https://apnews.com/article/the-facebook-paperswhistleblower-misinfo-trafficking-64f11ccae637cdfb 7 a 89 e 049 c5095 dca (Accessed October 27, 2021).

Pallavicini, F., Pepe, A., and Mantovani, F. (2021). Commercial Off-The-Shelf Video Games for Reducing Stress and Anxiety: Systematic Review. JMIR Ment. Health 8, e28150. doi:10.2196/28150

Paping, C., Brinkman, W.-P., and van der Mast, C. (2010). "An Explorative Study into a Tele-Delivered Multi-Patient Virtual Reality Exposure Therapy System," in Coping with Posttraumatic Stress Disorder in Returning Troops (Amsterdam, NY: IOS Press), 203-219.

Park, M. J., Kim, D. J., Lee, U., Na, E. J., and Jeon, H. J. (2019). A Literature Overview of Virtual Reality (VR) in Treatment of Psychiatric Disorders: Recent Advances and Limitations. Front. Psychiatry 10, 505. doi:10.3389/fpsyt.2019. 00505

Parker, L., Halter, V., Karliychuk, T., and Grundy, Q. (2019). How Private Is Your Mental Health App Data? an Empirical Study of Mental Health App Privacy Policies and Practices. Int. J. L. Psychiatry 64, 198-204. doi:10.1016/j.ijlp.2019. 04.002

Parsons, T. D. (2021). Ethical Challenges of Using Virtual Environments in the Assessment and Treatment of Psychopathological Disorders. J. Clin. Med. 10, 378. doi: $10.3390 / \mathrm{jcm} 10030378$

Parsons, T. D., and Rizzo, A. A. (2008). Affective Outcomes of Virtual Reality Exposure Therapy for Anxiety and Specific Phobias: a Meta-Analysis. J. Behav. Ther. Exp. Psychiatry 39, 250-261. doi:10.1016/j.jbtep.2007.07.007

Patel, P., Ivanov, D., Bhatt, S., Mastorakos, G., Birckhead, B., Khera, N., et al. (2020). Low-Cost Virtual Reality Headsets Reduce Perceived Pain in Healthy 
Adults: A Multicenter Randomized Crossover Trial. Games Health J. 9, 129-136. doi:10.1089/g4h.2019.0052

Pérez-Carbonell, L., Meurling, I. J., Meurling, I. J., Wassermann, D., Gnoni, V., Leschziner, G., et al. (2020). Impact of the Novel Coronavirus (COVID-19) Pandemic on Sleep. J. Thorac. Dis. 12, S163-S175. doi:10.21037/jtd-cus2020-015

Persky, S. (2020). A Virtual Home for the Virtual Clinical Trial. J. Med. Internet Res. 22, e15582. doi:10.2196/15582

Pierce, B. S., Perrin, P. B., Tyler, C. M., McKee, G. B., and Watson, J. D. (2020). The COVID-19 Telepsychology Revolution: A National Study of Pandemic-Based Changes in U.S. Mental Health Care Delivery. Am. Psychol. 76, 14-25. doi:10. 1037/amp0000722

Pimentel, D., Foxman, M., Davis, D. Z., and Markowitz, D. M. (2021). Virtually Real, but Not Quite There: Social and Economic Barriers to Meeting Virtual Reality's True Potential for Mental Health. Front. Virtual Reality 2, 2. doi:10. 3389/frvir.2021.627059

Pirkis, J., John, A., Shin, S., DelPozo-Banos, M., Arya, V., Analuisa-Aguilar, P., et al. (2021). Suicide Trends in the Early Months of the COVID-19 Pandemic: an Interrupted Time-Series Analysis of Preliminary Data from 21 Countries. The Lancet Psychiatry 8, 579-588. doi:10.1016/s2215-0366(21)00091-2

Pizzoli, S. F. M., Mazzocco, K., Triberti, S., Monzani, D., Alcañiz Raya, M. L., and Pravettoni, G. (2019). User-Centered Virtual Reality for Promoting Relaxation: An Innovative Approach. Front. Psychol. 10, 479. doi:10.3389/fpsyg.2019.00479

Ratcliffe, J., Soave, F., Bryan-Kinns, N., Tokarchuk, L., and Farkhatdinov, I. (2021). "Extended Reality (XR) Remote Research: a Survey of Drawbacks and Opportunities," in Proceedings of the 2021 CHI Conference on Human Factors in Computing Systems, New York, NY, USA, May 2021 (New York, NY: Association for Computing Machinery), 1-13.

Reeves, R., Curran, D., Gleeson, A., and Hanna, D. (2021). A Meta-Analysis of the Efficacy of Virtual Reality and In Vivo Exposure Therapy as Psychological Interventions for Public Speaking Anxiety. Behav. Modif., 145445521991102. doi:10.1177/0145445521991102

Rehm, I. C., Foenander, E., Wallace, K., Abbott, J.-A. M., Kyrios, M., and Thomas, N. (2016). What Role Can Avatars Play in E-Mental Health Interventions? Exploring New Models of Client-Therapist Interaction. Front. Psychiatry 7, 186. doi:10.3389/fpsyt.2016.00186

Reilly, S. E., Zane, K. L., McCuddy, W. T., Soulliard, Z. A., Scarisbrick, D. M., Miller, L. E., et al. (2020). Mental Health Practitioners' Immediate Practical Response during the COVID-19 Pandemic: Observational Questionnaire Study. JMIR Ment. Health 7, e21237. doi:10.2196/21237

Renn, B. N., Chu, F., and Zaslavsky, O. (2021). Telemental Health after COVID-19. J. Clin. Psychiatry 82. doi:10.4088/JCP.21lr14037

Riva, G., Morganti, F., and Villamira, M. (2004). Immersive Virtual Telepresence: Virtual Reality Meets eHealth. Stud. Health Technol. Inform. 99, 255-262. doi:10.3233/978-1-60750-943-1-255

Riva, G., Mantovani, F., and Wiederhold, B. K. (2020). Positive Technology and COVID-19. Cyberpsychology, Behav. Soc. Networking 23, 581-587. doi:10.1089/ cyber.2020.29194.gri

Rizzo, A. S., and Koenig, S. T. (2017). Is Clinical Virtual Reality Ready for Primetime. Neuropsychology 31, 877-899. doi:10.1037/neu0000405

Rizzo, A. S., Koenig, S. T., and Talbot, T. B. (2018). Clinical Virtual Reality: Emerging Opportunities for Psychiatry. Foc 16, 266-278. doi:10.1176/appi. focus.20180011

Rosenberg Danziger, C., Krause, I., Scheuerman, O., Luder, A., Yulevich, A., Dalal, I., et al. (2021). Pediatrician, Watch Out for corona-phobia. Eur. J. Pediatr. 180, 201-206. doi:10.1007/s00431-020-03736-y

Saad, A., Bruno, D., Camara, B., D’Agostino, J., and Bolea-Alamanac, B. (2021). Self-directed Technology-Based Therapeutic Methods for Adult Patients Receiving Mental Health Services: Systematic Review. JMIR Ment. Health 8, e27404. doi:10.2196/27404

Saeed, S. A., and Masters, R. M. (2021). Disparities in Health Care and the Digital Divide. Curr. Psychiatry Rep. 23, 61. doi:10.1007/s11920-021-01274-4

Šalkevičius, J., Miškinytè, A., and Navickas, L. (2019). Cloud Based Virtual Reality Exposure Therapy Service for Public Speaking Anxiety. Information 10, 62. doi:10.3390/info10020062

Salkevicius, J., and Navickas, L. (2018). "Battling the Fear of Public Speaking: Designing Software as a Service Solution for a Virtual Reality Therapy," in Proceeding of the 2018 6th International Conference on Future Internet of
Things and Cloud Workshops (FiCloudW), Barcelona, Spain, Aug. 2018 (IEEE), 209-213.

Salokangas, R. K. R., Luutonen, S., Heinimaa, M., From, T., and au, J. (2019). A Study on the Association of Psychiatric Diagnoses and Childhood Adversities with Suicide Risk. Nordic J. Psychiatry 73, 125-131. doi:10.1080/08039488.2018. 1493748

Sampaio, M., Navarro Haro, M. V., De Sousa, B., Vieira Melo, W., and Hoffman, H. G. (2021). Therapists Make the Switch to Telepsychology to Safely Continue Treating Their Patients during the COVID-19 Pandemic. Virtual Reality Telepsychology May Be Next. Front. Virtual Real. 1, 576421. doi:10.3389/ frvir.2020.576421

Samuels, J., Holingue, C., Nestadt, P. S., Bienvenu, O. J., Phan, P., and Nestadt, G. (2021). Contamination-related Behaviors, Obsessions, and Compulsions during the COVID-19 Pandemic in a United States Population Sample. J. Psychiatr. Res. 138, 155-162. doi:10.1016/j.jpsychires.2021.03.064

Saredakis, D., Szpak, A., Birckhead, B., Keage, H. A. D., Rizzo, A., and Loetscher, T. (2020). Factors Associated with Virtual Reality Sickness in Head-Mounted Displays: A Systematic Review and Meta-Analysis. Front. Hum. Neurosci. 14, 96. doi:10.3389/fnhum.2020.00096

Shah, K., Bedi, S., Onyeaka, H., Singh, R., and Chaudhari, G. (2020). The Role of Psychological First Aid to Support Public Mental Health in the COVID-19 Pandemic. Cureus 12, e8821. doi:10.7759/cureus.8821

Shin, B., Oh, J., Kim, B.-H., Kim, H. E., Kim, H., Kim, S., et al. (2021). Effectiveness of Self-Guided Virtual Reality-Based Cognitive Behavioral Therapy for Panic Disorder: Randomized Controlled Trial. JMIR Ment. Health 8, e30590. doi:10. 2196/30590

Singh, J. A., and Ravinetto, R. (2020). COVID-19 Therapeutics: How to Sow Confusion and Break Public Trust during International Public Health Emergencies. J. Pharm. Pol. Pract 13, 47. doi:10.1186/s40545-020-00244-0

Slater, M., Gonzalez-Liencres, C., Haggard, P., Vinkers, C., Gregory-Clarke, R., Jelley, S., et al. (2020). The Ethics of Realism in Virtual and Augmented Reality. Front. Virtual Real. 1, 1. doi:10.3389/frvir.2020.00001

Sorene, P. (2014). Jaron Lanier's EyePhone: Head and Glove Virtual Reality in the 1980s - Flashbak. Flaskbak. Available from: https://flashbak.com/jaron-lanierseyephone-head-and-glove-virtual-reality-in-the-1980s-26180/ (Accessed August 16, 2021).

Steidtmann, D., McBride, S., and Mishkind, M. C. (2020). Experiences of Mental Health Clinicians and Staff in Rapidly Converting to Full-Time Telemental Health and Work from Home during the COVID-19 Pandemic. Telemed. J. E. Health 27, 785-791. doi:10.1089/tmj.2020.0305

Stein, S. (2021). HTC's New VR Face Tracker Can Scan Your Lips, Tongue and Chin. San Francisco, CA: CNET. Available from: https://www.cnet.com/tech/computing/htcsnew-vr-face-tracker-can-scan-your-lips-tongue-and-chin/ (Accessed September 15, 2021).

Steinman, S. A., Wootton, B. M., and Tolin, D. F. (2016). "Exposure Therapy for Anxiety Disorders," in Encyclopedia of Mental Health. Editor H. S. Friedman. Second Edition (Oxford: Academic Press), 186-191. doi:10.1016/b978-0-12397045-9.00266-4

Stupar-Rutenfrans, S., Ketelaars, L. E. H., and van Gisbergen, M. S. (2017). Beat the Fear of Public Speaking: Mobile $360^{\circ}$ Video Virtual Reality Exposure Training in Home Environment Reduces Public Speaking Anxiety. Cyberpsychology, Behav. Soc. Networking 20, 624-633. doi:10.1089/cyber. 2017.0174

Supan, J. (2021). New Report States US Has World's 11th Fastest Internet. Fort Mill, SC: allconnect. Available from: https://www.allconnect.com/blog/us-internetspeeds-globally Accessed September 21, 2021).

Sykownik, P., Graf, L., Zils, C., and Masuch, M. (2021). "The Most Social Platform Ever? A Survey about Activities Amp; Motives of Social VR Users," in Proceeding of the 2021 IEEE Virtual Reality and 3D User Interfaces (VR), Lisboa, Portugal, April 2021 (IEEE), 546-554.

Tabbaa, L., Ang, C. S., Siriaraya, P., She, W. J., and Prigerson, H. G. (2020). A Reflection on Virtual Reality Design for Psychological, Cognitive and Behavioral Interventions: Design Needs, Opportunities and Challenges. Int. J. Human-Computer Interaction 37 (9), 851-866. doi:10.1080/10447318.2020. 1848161

Tao, G., Garrett, B., Taverner, T., Cordingley, E., and Sun, C. (2021). Immersive Virtual Reality Health Games: a Narrative Review of Game Design. J. Neuroengineering Rehabil. 18, 31. doi:10.1186/s12984-020-00801-3 
Taylor, D. B. (2021). George Floyd Protests: A Timeline. New York, NY: The New York Times. Available from: https://www.nytimes.com/article/george-floydprotests-timeline.html (Accessed August 6, 2021).

The Economist (2021). Crypto-miners Are Probably to Blame for the Graphics-Chip Shortage. New York, NY: The Economist. Available from: https://www.economist.com/graphicdetail/2021/06/19/crypto-miners-are-probably-to-blame-for-the-graphics-chip-shortage (Accessed September 21, 2021).

The Lancet Infectious Diseases (2020). The COVID-19 Infodemic. Lancet Infect. Dis. 20, 875. doi:10.1016/S1473-3099(20)30565-X

Timothy Zhang, T., Booth, R., Jean-Louis, R., Chan, R., Yeung, A., Gratzer, D., et al. (2020). A Primer on Usability Assessment Approaches for Health-Related Applications of Virtual Reality. JMIR Serious Games 8, e18153. doi:10.2196/18153

Tuena, C., Pedroli, E., Trimarchi, P. D., Gallucci, A., Chiappini, M., Goulene, K., et al. (2020). Usability Issues of Clinical and Research Applications of Virtual Reality in Older People: A Systematic Review. Front. Hum. Neurosci. 14, 93. doi:10.3389/fnhum.2020.00093

Tuerk, P. W., Schaeffer, C. M., McGuire, J. F., Adams Larsen, M., Capobianco, N., and Piacentini, J. (2019). Adapting Evidence-Based Treatments for Digital Technologies: a Critical Review of Functions, Tools, and the Use of Branded Solutions. Curr. Psychiatry Rep. 21, 106. doi:10.1007/s11920-019-1092-2

Uscher-Pines, L., Sousa, J., Raja, P., Mehrotra, A., Barnett, M. L., and Huskamp, H. A. (2020). Suddenly Becoming a "Virtual Doctor": Experiences of Psychiatrists Transitioning to Telemedicine during the COVID-19 Pandemic. Psychiatr. Serv. 71, 1143-1150. doi:10.1176/appi.ps.202000250

Vinograd, M., and Craske, M. G. (2020). in History and Theoretical Underpinnings of Exposure Therapy Exposure Therapy for Children with Anxiety and OCD. Editors T. S. Peris, E. A. Storch, and J. F. McGuire (Academic Press), 3-20. doi:10.1016/b978-0-12-815915-6.00001-9

Wanling Zhang, W., Paudel, D., Shi, R., Liang, J., Liu, J., Zeng, X., et al. (2020). Virtual Reality Exposure Therapy (VRET) for Anxiety Due to Fear of COVID19 Infection: A Case Series. Neuropsychiatr. Dis. Treat. 16, 2669-2675. doi:10. 2147/ndt.s276203

Wardenaar, K. J., Lim, C. C. W., Al-Hamzawi, A. O., Alonso, J., Andrade, L. H., Benjet, C., et al. (2017). The Cross-National Epidemiology of Specific Phobia in the World Mental Health Surveys. Psychol. Med. 47, 1744-1760. doi:10.1017/ s0033291717000174

Wechsler, T. F., Kümpers, F., and Mühlberger, A. (2019). Inferiority or Even Superiority of Virtual Reality Exposure Therapy in Phobias?-A Systematic Review and Quantitative Meta-Analysis on Randomized Controlled Trials Specifically Comparing the Efficacy of Virtual Reality Exposure to Gold Standard In Vivo Exposure in Agoraphobia, Specific Phobia, and Social Phobia. Front. Psychol. 10, 1758. doi:10.3389/fpsyg.2019.01758

Wersebe, H., Lieb, R., Meyer, A. H., Miche, M., Mikoteit, T., Imboden, C., et al. (2018). Well-being in Major Depression and Social Phobia with and without Comorbidity. Int. J. Clin. Health Psychol. 18, 201-208. doi:10.1016/j.ijchp.2018.06.004

Whaibeh, E., Mahmoud, H., and Naal, H. (2020). Telemental Health in the Context of a Pandemic: the COVID-19 Experience. Curr. Treat. Options. Psychiatry 7, 198-2020. doi:10.1007/s40501-020-00210-2
Wickens, K. (2021). Oculus Quest 2 Is Now the Most Popular VR Headset Around. New York, NY: PC Gamer. Available from: https://www.pcgamer.com/oculusquest-2-knocks-rift-s-off-top-spot/ (Accessed September 29, 2021).

Wiederhold, B. K., and Riva, G. (2019). Virtual Reality Therapy: Emerging Topics and Future Challenges. Cyberpsychology, Behav. Soc. Networking 22, 3-6. doi:10.1089/cyber.2018.29136.bkw

Willis, D. E., Andersen, J. A., Bryant-Moore, K., Selig, J. P., Long, C. R., Felix, H. C., et al. (2021). COVID-19 Vaccine Hesitancy: Race/ethnicity, Trust, and Fear. Clin. Transl. Sci. 14, 2200-2207. doi:10.1111/cts.13077

Wolitzky-Taylor, K. B., Horowitz, J. D., Powers, M. B., and Telch, M. J. (2008). Psychological Approaches in the Treatment of Specific Phobias: a MetaAnalysis. Clin. Psychol. Rev. 28, 1021-1037. doi:10.1016/j.cpr.2008.02.007

Wood, D. P., Murphy, J., McLay, R., Koffman, R., Spira, J., Obrecht, R. E., et al. (2009). Cost Effectiveness of Virtual Reality Graded Exposure Therapy with Physiological Monitoring for the Treatment of Combat Related post Traumatic Stress Disorder. Stud. Health Technol. Inform. 144, 223-229. doi:10.3233/9781-60750-017-9-223

Wu, T., Jia, X., Shi, H., Niu, J., Yin, X., Xie, J., et al. (2021). Prevalence of Mental Health Problems during the COVID-19 Pandemic: A Systematic Review and Meta-Analysis. J. Affective Disord. 281, 91-98. doi:10.1016/j.jad.2020.11.117

Xiong, J., Lipsitz, O., Nasri, F., Lui, L. M. W., Gill, H., Phan, L., et al. (2020). Impact of COVID-19 Pandemic on Mental Health in the General Population: A Systematic Review. J. Affective Disord. 277, 55-64. doi:10.1016/j.jad.2020.08.001

Yakobi, M., and Cheng Md, D. (2021). Retrospective Analysis of the Effects of the COVID-19 Pandemic on the Emergency Department Walk-Out Rate in an Acute Care Community Hospital during the USA National Lockdown. Cureus 13, e16660. doi:10.7759/cureus. 16660

Conflict of Interest: TO, HW, HS, QN, SP, JB, BW, and BB were employed by Doxy me Inc.

The remaining authors declare that the research was conducted in the absence of any commercial or financial relationships that could be construed as a potential conflict of interest.

Publisher's Note: All claims expressed in this article are solely those of the authors and do not necessarily represent those of their affiliated organizations, or those of the publisher, the editors and the reviewers. Any product that may be evaluated in this article, or claim that may be made by its manufacturer, is not guaranteed or endorsed by the publisher.

Copyright (C) 2022 Ong, Wilczewski, Soni, Nisbet, Paige, Barrera, Welch and Bunnell. This is an open-access article distributed under the terms of the Creative Commons Attribution License (CC BY). The use, distribution or reproduction in other forums is permitted, provided the original author(s) and the copyright owner(s) are credited and that the original publication in this journal is cited, in accordance with accepted academic practice. No use, distribution or reproduction is permitted which does not comply with these terms. 